\title{
A divulgação de acervos arquivísticos na Web: potencialidades da perspectiva de User Experience aplicada ao Sistema de Informações do Arquivo Nacional
}

\author{
The outreach of archival collections on the Web: potentialities of the User Experience's \\ perspective applied to the National Archives Information System
}

\author{
Bianca da Costa Maia Lopes \\ Doutoranda em Ciência da Informação \\ Universidade Federal do Rio de Janeior \\ bianca.lopes@gmail.com \\ Eliezer Pires da Silva \\ Doutor em Memória Social \\ Universidade Federal do Estado do Rio de Janeiro \\ eliezerpires@gmail.com
}

\begin{abstract}
Resumo
Ante o despontar das tecnologias digitais, a disponibilidade dos recursos informacionais da rede mundial de computadores suscitou novas possibilidades de comunicar os acervos arquivísticos ao seu público. Nesse cenário, a potencialidade de tais recursos ampliou os horizontes de busca e recuperação da informação dos arquivos, produzindo efeitos sobre a difusão de seus acervos. O presente trabalho aborda o fenômeno de uma nova geração de instrumentos arquivísticos de referência, a partir do caso do Sistema de Informações do Arquivo Nacional (SIAN), principal instrumento de referência disponibilizado pelo Arquivo Nacional, sob a ótica de User Experience (UX) Design. Parte-se de revisão bibliográfica e, em seguida, promove-se a coleta e análise de dados segundo uma adaptação de métodos empíricos com normas de usabilidade. A partir dos resultados obtidos, buscou-se compreender a percepção dos usuários acerca dessa ferramenta e identificar seus recursos e funcionalidades passíveis de alterações, a fim de facilitar e otimizar a experiência dos usuários. Os resultados indicam uma insuficiência dos instrumentos de referência online das instituições arquivísticas para atingir seu amplo público, em que pesem os critérios de inteligibilidade, operacionalidade e satisfação dos usuários.
\end{abstract}

\section{Palavras-chave}

Descrição arquivística. Difusão em arquivos. Instrumentos de referência. User Experience.

\begin{abstract}
In the face of the emergence of digital technologies, the availability of the informational resources in the world wide web has given rise to new possibilities of communicating archival collections to its public. In this context, the potentiality of such resources broadened the horizons of information search and retrieval of the archives, producing effects on the diffusion of its collections. The present work broaches the phenomenon of the so-called next generation of finding aids, based on the National Archives Information System (NAIS), the main reference instrument available by the National Archives of Brazil, undertaking an investigation through the perspective of User Experience (UX) Design. Starting from a literature review, it promotes a data collection and analysis according to the


adaptation of empirical methods and usability norms. From the results obtained, the main goal was to understand the users' perception of the tool and to identify its changeable resources and features, in order to facilitate and optimize the users' experience. The results point to an insufficiency of the online reference instruments of the archival institutions to reach a wider public, considering the criteria of intelligibility, operability and user satisfaction.

\section{Keywords}

Archival description. Diffusion of archives. Reference instruments. User Experience.

\section{INTRODUÇÃO}

Tradicionalmente, os arquivos surgem revestidos pela aura soturna do que é privado, sagrado, oculto, desconhecido. Desde a Antiguidade, a prática de preservar e depositar documentos em lugares "seguros" macula os arquivos como posses preciosas, raridades, verdadeiros tesouros velados. Antes de lieux de mémoire (NORA, 1993), os arquivos são lugares de negação, de encobrimento: resguardam longínquas ilhas de segredos, propendem historicamente à exclusividade, à exclusão.

Nesse bojo, o exercício de pensar sua difusão pressupõe o entendimento de que não se trata de um processo natural; dar a conhecer os arquivos ao público vai de encontro à concepção patrimonial, religiosa e sigilosa que os circunda. Se tal lógica remete à opacidade, como alcançar a visibilidade dos arquivos?

Em que pese o seu caráter científico, o Leitmotiv da Arquivologia não é outro senão a disponibilização dos arquivos à sociedade, constituída pela comunicação do conteúdo informacional dos documentos de arquivo. Por tal prisma, difundir os arquivos implica fortalecer, de modo pragmático, o direito constitucional de aceder à informação e, por conseguinte, à cultura e à memória.

Ainda que o sentido precípuo dos arquivos seja evidenciado na especificidade do caráter probatório e testemunhal de seus documentos, seu contorno científico exorbita as relações fronteiriças com a administração, o direito, a cidadania e a historiografia (BELLOTTO, 2006). Os usos multiformes das informações que armazenam transpassam tecnologias digitais cada vez mais ubíquas e, potencialmente, empoderadoras.

Em sociedades democráticas, o acesso à informação é condição sine qua non para que a população dela se aproprie. Por essa acepção, a difusão dos arquivos demarca um viés politizante e almeja a uma sociedade mais transparente, plural e informada, cujo projeto seria o acesso e compreensão de todos ao conhecimento que, atualmente, poucos partiIham.

Sem embargo, uma plena apropriação extrapola o mero provimento de acesso físico ou virtual aos documentos de arquivo, contemplando, ainda, seu entendimento pelo chamado cidadão comum, aquele que é leigo ou não especialista no campo arquivístico. Dessa forma, a inteligibilidade se revela essencial para que a informação contida nos arquivos confira a estes uma conotação crítica e social, presumindo-se a compreensão esclarecida de seu conteúdo.

Para tanto, dentre as finalidades mediatas da área, a difusão arquivística subentende predicados que perpassam a etapa de descrição arquivística, comportando tanto seu processo como seu produto. No âmbito dessa etapa, destaca-se que a formulação de instrumentos arquivísticos de referência visa a abarcar a reconstrução do contexto arquivístico, a fim de 
representar e disponibilizar as informações sobre os acervos custodiados ao público dos arquivos (OLIVEIRA, 2010).

Contemporaneamente, a emergência de uma nova geração de instrumentos de referência online envolve aspectos de ordem tanto tecnológica quanto comunicacional, suscitando uma potencial ampliação do uso social dos acervos de instituições arquivísticas. Além disso, essa geração de instrumentos de referência reverbera a emergência do paradigma tecnológico qualificado pelas chamadas Tecnologias de Informação e Comunicação (TIC).

Com efeito, as tecnologias digitais produzem significativas mudanças no âmbito da difusão dos acervos arquivísticos, alterando padrões e comportamentos daqueles que os utilizam. Uma gama de recursos técnicos disponibilizados pela internet amplia os meios de busca e acesso às informações entre arquivos e seu público.

Situar os arquivos neste contexto tecnológico - que também não se furta de ser econômico, tecnopolítico e social - presume reconhecer o alargamento das perspectivas contemporâneas do pensamento arquivístico, enoveladas por múltiplos e fecundos campos do saber. Nesse horizonte, sustenta-se que a interlocução entre a Arquivologia e as áreas afetas ao User Experience (UX) Design oportuniza contribuições teóricas e práticas ao campo dos arquivos, em especial, à descrição e difusão arquivísticas.

Nessa direção, o presente artigo realça como questão compreender de que forma a navegabilidade de instrumentos de referência online afeta o propósito de difusão dos acervos arquivísticos, considerando a usabilidade e a inteligibilidade desses instrumentos na rede. Investiga-se a experiência de uso do Sistema de Informações do Arquivo Nacional (SIAN), principal base de dados do Arquivo Nacional brasileiro (AN), tendo em vista a importância da interface usuário-sistema para a difusão arquivística, a fim de verificar se tal ferramenta atende, efetivamente, ao propósito de difusão de acervos arquivísticos à sociedade, em que pese a sua compreensão esclarecida pelos usuários.

Trata-se de pesquisa exploratória qualitativa aplicada, cujo percurso metodológico parte da revisão bibliográfica sobre a descrição e a difusão arquivísticas, a evolução da web e estudos sobre UX Design e usabilidade, recorrendo-se a diversos autores das respectivas áreas. Após a delimitação e contextualização do campo empírico, procedeu-se à coleta de dados por meio de questionário do tipo web-survey, promovendo-se uma verificação empírica da percepção dos usuários sobre o SIAN conforme suas experiências de uso.

Admite-se, sobretudo, que o potencial comunicacional dos arquivos abarcado pela difusão pode ser dilatado a partir da convergência teórica entre a Arquivologia e as diversas áreas afetas às tecnologias digitais, a exemplo da Arquitetura da Informação e do Design de Interação. Em especial, o aporte da perspectiva de UX sobre a nova geração de instrumentos de referência deve ser mais bem explorado, a fim de reforçar os elos interdisciplinares entremeados à ciência dos arquivos.

\section{DESCRIÇÃO ARQUIVÍSTICA: PROCESSO OU PRODUTO?}

Em meio a diversos sentidos atribuídos à descrição arquivística, destaca-se sua manifestação como uma atividade intelectual que visa a refletir a utilização de processos e métodos do campo, a fim de representar as informações contidas nos acervos arquivísticos, evidenciando seu conteúdo e contexto. Nesta acepção, a descrição é também compreendida como uma forma de representação dos arquivos, tal qual pensada pela norte-americana Elizabeth Yakel (2003): 
O termo "representação arquivística" capta, mais precisamente, os papeis do arquivista em reordenar, interpretar, criar substitutos e desenhar arquiteturas para sistemas de representação que contenham esses substitutos para suprir ou representar os próprios materiais arquivísticos. (YAKEL, 2003, p. 2, tradução nossa).

Em consulta à base de dados on-line Multilingual Archival Terminology ${ }^{1}$ pelo termo description não foram encontraram definições, apenas uma remissão ao termo archival description, este apresentando quatro definições: duas o mostram como um processo e outras duas o aproximam à criação de uma representação.

Ao recorrer à definição do Dicionário Brasileiro de Terminologia Arquivística, o termo descrição consiste no "conjunto de procedimentos que leva em conta os elementos formais e de conteúdo dos documentos para elaboração de instrumentos de pesquisa" (ARQUIVO NACIONAL, 2005, p. 67). Embora pertinente, tal definição acomoda um aspecto redutor ao associar a descrição arquivística apenas à produção dos instrumentos de pesquisa, preterindo-se outros produtos também derivados do processo descritivo (OLIVEIRA, 2010).

Dessa maneira, Oliveira (2010) situa os instrumentos de pesquisa como produtos correspondentes somente a uma parte desse processo, salientando que não contemplariam todo o conhecimento produzido pelo arquivista sobre o acervo. Uma dissociação entre ambos os conceitos também é percebida por Llanes Padrón (2016), similarmente, no âmbito da emergência de novas tecnologias na contemporaneidade.

A evolução tecnológica alcançada nas últimas décadas do século XX permitiu disso-
ciar o conceito de descrição do conceito de instrumento de pesquisa. A descrição
consiste em elaborar uma representação (atividade) que pode ter diferentes for-
mas de manifestação (instrumentos de consulta); a partir de uma base de dados
descritiva é possível obter diferentes formatos de saída (várias formas de exibição
na tela ou diferentes tipos de impressos). (LLANES PADRÓN, 2016, p. 27, tradução
nossa).

Digno de nota é que, de maneira geral, a falta de consenso quanto a essa questão decorre da forma pela qual a descrição é considerada pela literatura da área: para alguns autores, um produto; para outros, um processo.

Sob a ótica de Yeo (2016, p. 135), os debates acerca da descrição arquivística apontam para a sua compreensão tanto como um processo quanto um produto. $O$ autor relata que as percepções da comunidade arquivística sobre a descrição diferem quanto à ênfase atribuída a seus papeis e funções: visões distintas tendem a reforçar aspectos como o controle, o acesso, a autenticidade ou o contexto. Porém, não se tratam de perspectivas incompatíveis, necessariamente, mas complementares.

Para Oliveira (2010, p. 43), apesar da literatura da área identificar como finalidades da descrição, tradicionalmente, o controle e o acesso do acervo, diversos elementos compõem camadas de compreensão para a representação do contexto arquivístico, reforçando a cientificidade da descrição dos arquivos e sua abordagem como função de pesquisa.

Já ao recompor os aspectos históricos da descrição arquivística, Andrade e Silva (2008, p. 17) realçam a importância da relação entre conhecer o contexto e o resultado dessa atividade, indicando a necessidade desse processo abarcar tanto elementos sobre o contexto de criação, como outros extraídos do próprio conjunto documental descrito. Assim, o

\footnotetext{
${ }^{1}$ Criada e disponibilizada pelo Conselho Internacional de Arquivos (CIA), essa base de dados facilita a comunicação e a compreensão dos conceitos relacionados aos documentos em diversos idiomas, culturas e tradições da prática arquivística.
} 
trabalho do arquivista contemplaria a descrição do conteúdo, da estrutura e do contexto dos documentos, preservando a imparcialidade e a autenticidade do documento de arquivo.

Por sua vez, Duranti (2011) sublinha a relação entre a descrição arquivística e a autenticidade, tratando aquela como uma comprovação da autenticidade de documentos de um fundo e de todas as suas inter-relações: "o único papel importante que os arquivistas têm em relação à autenticidade é descrever os documentos sob sua custódia em contexto, tornando explícita, estabilizando e perpetuando seus relacionamentos com seus criadores e entre eles [...]." (DURANTI, 2011, p. 78, tradução nossa). A italiana corrobora, assim, o ponto de vista de Yeo (2016), pelo qual afirma que os autores que enfatizam o contexto ou a autenticidade da descrição demonstram privilegiar um enfoque sobre a presunção de prova dos documentos e as ações que os produzem.

Depreende-se que cumpriria ao arquivista, ao operacionalizar o processo descritivo, compreender o contexto dos documentos de arquivo descritos, bem como a interação entre a unidade de informação arquivística e os seus usuários. Para tanto, a criação e aplicação de normas específicas são evidenciadas em levantamento bibliográfico de Oliveira (2010), abarcando desde o Manual de Arranjo e Descrição de Arquivos (vulgo Manual dos Arquivistas Holandeses), em 1898, até o Describing archives: a content standard (DACS), em 2008. Em especial, sobreleva-se que a ISAD(G): Norma Geral Internacional de Descrição Arquivística, em 2003, subsidiou o desenvolvimento da Norma Brasileira de Descrição Arquivística (NOBRADE) pelo Conselho Nacional de Arquivos (CONARQ), em 2006.

Cabe ressaltar que, em 2012, o Conselho Internacional de Arquivos (CIA) constituiu um grupo de trabalho com 21 especialistas em descrição arquivística, oriundos de 13 países distintos, visando à promoção de melhores práticas nesta temática. Entre 2012 e 2016, o grupo buscou desenvolver um padrão descritivo para conciliar, integrar e construir um modelo a partir das quatro normas de descrição - ISAD(G), ISAAR(CPF), ISDF e ISDIAH -, intitulado Records in Context (RiC). Ainda em 2016, na forma de rascunho, o modelo conceitual proposto foi submetido à comunidade arquivística para consulta pública, tendo recebido contundentes críticas pelo InterPARES Trust (2016).

Em que pese a variedade de críticas que lhe foram endereçadas, enfatiza-se uma que se refere ao foco sobre o papel dos usuários na proposição dessa modelagem:

\footnotetext{
O papel dos usuários tem sido cada vez mais um tópico de investigação na literatura científica desses últimos anos. Novas tecnologias oferecem novas e inimagináveis possibilidades de interação com instrumentos de pesquisa, sugerindo, por um lado, a necessidade de reconsiderar e redefinir o papel de instrumentos de pesquisa e, por outro; o papel dos usuários. Os usuários devem ser uma preocupação primária de qualquer projeto que trate de descrição. Este foco nos usuários deve ser preliminar para qualquer definição de elementos de descrição. (InterPARES Trust, 2016, p. 7, tradução nossa).
}

À medida que os usuários dos arquivos se relacionam com os acervos descritos na etapa de difusão, julga-se imperativo incluir sua perspectiva em debates sobre a descrição arquivística e suas normas. Do mesmo modo, é oportuno compreender a conjuntura tecnológica que perpassa as relações entre esses usuários ao aceder às informações contidas nos acervos arquivísticos.

É essencial, contudo, não perder de vista os limites discursivos de construção dos modelos para a descrição arquivística. Como sinaliza MacNeil (2005), a representação arquivística é seletiva e incapaz de envolver o todo que pretende descrever. Ou, ainda, segundo Foucault (2010, p. 148), "é óbvio que o arquivo de uma sociedade, de uma cultura, ou de 
uma civilização não pode ser descrito de maneira exaustiva [...] $\mathrm{O}$ arquivo não pode ser descrito em sua totalidade". Nessa lógica, reitera-se que o processo modelizador dessa atividade não deve preterir as mudanças tecnológicas e os seus impactos na produção de instrumentos de referência, tampouco o peso da atuação do usuário nessa interação.

Avançando pela definição inicial mencionada por Yakel (2003), a autora aponta que "o próprio ato de representação arquivística, projetado para solicitar e fornecer acesso a acervos através de instrumentos de pesquisa, também pode criar barreiras para o uso" (YAKEL, 2003, p. 2, tradução nossa). Nesse sentido, é vital que os pesquisadores conheçam e compreendam os esquemas, códigos e linguagens que envolvem os sistemas implícitos de privilegiar, classificar e selecionar: ainda que regidos por normas, remetem a um reconhecido grau de subjetividade. Segundo Yeo (2016, p. 149):

[...] os arquivistas estão cada vez mais convencidos de que a representação nunca é perfeita, de que concessões precisam ser feitas, de que as normas não são universais, mas produtos localizados de sociedades específicas [...]. Mas já que o trabalho descritivo é necessariamente seletivo, os arquivistas também tomam decisões conscientes sobre o que incluir em suas descrições, o que enfatizar e o que ignorar, e essas decisões inevitavelmente privilegiam alguns aspectos em detrimento de outros.

No escopo desta investigação, destaca-se a relevância do papel da descrição dos arquivos com ênfase sobre o acesso, uma vez que essa função se entrelaça com a participação dos usuários e suas demandas por informações, sendo fundamental para a difusão do conteúdo dos arquivos. Destarte, infere-se que a descrição arquivística comporta um processo e também os seus respectivos produtos, dentre os quais se incluem os instrumentos de referência.

\section{DIFUSÃO ARQUIVÍSTICA: DO CONCEITO À AÇÃO}

Concebida como uma das funções arquivísticas (ROUSSEAU; COUTURE, 1998, p. 265), a difusão dos arquivos representa uma estratégia vital para a sua projeção ante a sociedade, a partir do desenvolvimento de atividades que encurtem o distanciamento entre as instituições arquivísticas e seu público em geral. Digno de nota é que tais autores não chegam a definir o que se entende por essa função. Afinal, do que fala a Arquivologia quando fala em difusão?

Ao investigar a base de dados on-line Multilingual Archival Terminology, averigua-se que a definição constante para o termo difusão é proveniente de Portugal, remetendo às "Normas Portuguesas de Documentação e Informação CT7". A partir de tal definição, depreende-se a "função do serviço de arquivo que visa promover o conhecimento do respectivo acervo documental". Curiosamente, o termo não fora definido pelo Dicionário Brasileiro de Terminologia Arquivística (DIBRATE), embora apareça na definição do termo "disseminação da informação". É no mínimo sintomático que uma das funções arquivísticas não apresente definição dicionarizada.

Como termo relacionado à difusão, em português, essa base de dados aponta divulgação. Ao buscá-lo, encontra-se a definição do DIBRATE, correspondendo ao "conjunto de atividades destinadas a aproximar o público dos arquivos, por meio de publicações e da promoção de eventos, como exposições e conferência". Em seguida, navegando-se pelo termo relacionado à divulgação, em língua inglesa, encontra-se outreach program, a partir do qual são apresentados outros termos relacionados multilíngues. 
Conforme as variações de cada língua, distintas nuances da difusão são apreendidas, a exemplo da conotação cultural francesa (action culturelle), a pedagógica alemã (Archivpädagogik) e a educacional holandesa (archiefeducatie). Nessa direção, caminha-se ao encontro das reflexões de Bellotto (2006), ao sinalizar que aos arquivos públicos cabem três formas de difusão: editorial, cultural e educativa, papel este que delineia seus contornos sociais e os projetam na comunidade.

O arquivo é a "consciência histórica" da administração. Também pode sê-lo relativamente à comunidade, se souber captar as potencialidades que, nesse sentido, Ihe oferece seu acervo. A par da cultura tradicional, os arquivos podem enveredar pelo caminho da divulgação verdadeiramente popular, sem se esquecer do constante reaquecimento de suas relações com seus usuários correntes: os pesquisadores - os cidadãos comuns ou historiadores. (BELLOTTO, 2006, p. 228).

Vale destacar três aspectos da visão da autora: o dimensionamento social dos arquivos, em paralelo às suas funções precípuas de custódia, preservação, tratamento e organização dos fundos arquivísticos, atreladas ao apoio às atividades da administração pública; a potencialidade dos arquivos em relação à comunidade, isto é, o que podem vir a ser e representar, incluindo a potencialidade dos arquivos comunicarem seus acervos; e, por último, quando a autora destaca que os arquivos podem se embrenhar no caminho de uma "divulgação verdadeiramente popular", nota-se que, no âmbito da sua difusão, há espaço para uma perspectiva que relaciona o ato de divulgar ao caráter popular.

Em sua visão, a difusão educativa compreenderia um serviço educativo da própria instituição arquivística, por meio de visitas escolares e ações que visem a dar a conhecer os acervos custodiados, revestida por uma qualidade didática. A difusão cultural contemplaria eventos não apenas sobre o fenômeno arquivístico, mas também sobre outras temáticas culturais, com inspiração no conteúdo do acervo institucional. Para Berche (apud CRUCES BLANCO, 2007, p. 15), deve-se reconhecer que "nossa época não descobriu o papel da difusão cultural, esta remonta a segunda metade do século XIX para encontrar os primeiros indícios de abertura dos arquivos para um público não erudito". Já a difusão editorial consistiria nas publicações, consideradas canais de comunicação com o exterior (da Arquivologia), posto que informam a comunidade, a administração e a academia sobre o acervo documental. Ponto importante é que Bellotto (2006) considera os instrumentos de pesquisa como um gênero de publicação, pois propiciam o acesso do pesquisador ao documento primário. Nessa acepção, a autora considera o historiador, o administrador e o cidadão e afirma:

Ora, a nenhum deles será possibilitado o acesso à informação requerida se não lhes for possível conhecer o conteúdo dos documentos do arquivo, sua tipologia, o órgão que os produziu e as inter-relações existentes entre eles. Isso só se realiza por meio da publicação de instrumentos de pesquisa, que são o elo entre os documentos procurados e o usuário. (BELLOTTO, 2006, p. 230).

Já Oliveira (2010) aborda a difusão dos arquivos ao abranger a atividade de descrição:

Como atividade científica, a descrição arquivística deve abarcar todas as etapas de pesquisa e análise, bem como prever o registro e divulgação do conhecimento produzido em todas essas etapas. A documentação sobre todo o processo é essencial para que o acesso à informação e aos documentos ocorra assegurando a difusão do conhecimento sobre os arquivos e oferecendo autonomia ao usuário. (OLIVEIRA, 2010, p. 54). 
Para esta autora, a formulação de instrumentos de pesquisa deve abranger a reconstrução do contexto arquivístico para representar e disponibilizar as informações sobre os acervos ao público dos arquivos, mediante a etapa de descrição arquivística. Ao compreendê-la como uma sorte de projeto de pesquisa para a produção de conhecimento sobre esses acervos, os instrumentos de pesquisa figuram como produtos científicos que são meio de divulgação e acesso aos acervos arquivístivos.

Por sua vez, Herrera (1991) aborda as funções de "transmitir, difundir e servir" das ciências da documentação. Ainda que a obra seja voltada aos documentalistas, ante a tradição da abordagem espanhola, a autora inclui os arquivos em sua visão. Chama atenção para a dinamização da difusão e afirma que esta "[...] não tem outro objetivo senão o serviço aos usuários através da comunicação da informação dos documentos" (HERRERA, 1991, p. 161, tradução nossa).

Cruces Blanco (2007) ressalta que a presença a finalidade do termo difusão consistiria em "[...] por um lado, promover a utilização dos fundos documentais dos arquivos e, por outro, participar a sociedade do papel que os arquivos desempenham nela" (CRUCES BLANCO, 2007, p. 4, tradução nossa).

Ao apontar estratégias para a ampliação do uso social dos arquivos, Alberch i Fugueras (2000, p. 6) indaga se é possível tornar inteligível a um amplo público a informação sistematizada por instrumentos de descrição arquivística, bem como o que deveria mudar para facilitar a compreensão e utilização dos instrumentos que, apesar de refletirem uma organização de arquivos exemplar do ponto de vista profissional, demonstram-se opacos para a maioria do público não especializado. Por esse prisma, infere-se que o autor acredita que os instrumentos de pesquisa tal qual concebidos não atendem à multiplicidade de demandas de seus usuários.

Ainda na década de 1980, Duchein (1983) aborda os obstáculos que se opõem ao acesso, à utilização e à transferência da informação custodiada nos arquivos. Ao expor barreiras que dificultam a acessibilidade aos arquivos, atenta para a publicidade do conhecimento do conteúdo dos arquivos: "de nada serviriam leis e regulamentos que garantam a liberdade de acesso aos arquivos se a existência e o conteúdo de deus documentos permanecem ignorados pelo público" (DUCHEIN, 1983, p. 39, tradução nossa).

À medida que os arquivos não alcançam o amplo público, escapam ao seu sentido precípuo. Duchein (1983) ilumina o cenário problemático de sua época, não tão distante do atual:

Em geral, salvo raras exceções, os arquivos são pouco conhecidos pelo público; apenas os historiadores e os administradores sabem o que contêm e como acessar o material que conservam. [...] Pode-se afirmar que, em quase todas as partes, os arquivos constituem um tesouro ignorado. (DUCHEIN, 1983, p. 39, tradução nossa).

Mais de três décadas após a publicação do autor, observa-se que há, no cenário brasileiro, o aumento da preocupação das instituições arquivísticas quanto à difusão dos arquivos. Segundo Rockembach (2015, p. 105), a complexidade que uma perspectiva arquivística emergente acarreta requer novos olhares e estudos sobre a difusão, atentando-se para três elementos: o usuário da informação, o conteúdo a ser difundido e o uso das tecnologias de e informação e comunicação.

Oliveira (2010) também salienta o uso crescente da web como plataforma para a divulgação dos acervos e a mudança de perfil dos usuários, nos últimos anos, como pontos a serem incorporados pelas discussões da área. Nesse contexto, afirma a autora: 
Se antes a divulgação dos instrumentos de pesquisa, resultado da descrição arquivística, era realizada por meio da publicação dos inventários e catálogos, com o advento da tecnologia web cada vez mais as instituições arquivísticas fazem uso desse território virtual para assegurar a visibilidade institucional e de seus acervos (OLIVEIRA, 2010, p. 54).

Nesse sentido, Rockembach (2015, p. 113) elenca estratégias da difusão dos arquivos que caminham ao encontro de uma perspectiva interdisciplinar, a partir da acessibilidade, transparência e compreensão do público e suas competências informacionais, visando à mediação do conteúdo dos arquivos a partir de três eixos: os usuários, o conteúdo e a tecnologia.

Observa-se, em geral, a existência de uma lacuna na literatura arquivística quanto à definição do termo difusão. Ressalva-se que há pesquisas sobre tal função na área, porém, ainda são escassas e carecem de maior aprofundamento, demonstrando certa fragilidade tanto de sua teoria como de sua prática.

\section{WEB 2.0 E UX DESIGN: CAMINHOS PARA A DIFUSÃO DOS ACERVOS ARQUIVÍSTICOS}

No contexto arquivístico, a disponibilidade de novos recursos informacionais ampliou os horizontes de busca e recuperação da informação e estremeceu a tradicional relação entre usuário e informação. Os usuários dos arquivos, antes agentes passivos na comunicação com as instituições arquivísticas, passam a figurar tanto como produtores quanto receptores da informação, conforme as suas necessidades específicas.

Nessa direção, a arquivista norte-americana Kate Theimer (2011b) propõe o termo "Arquivos 2.0" para se referir a uma abordagem da prática arquivística que estimula a promoção de abertura e flexibilidade, descartando a mera associação dos arquivos à geração específica da Web 2.0 ou como uma perspectiva puramente tecnológica, futurista. A partir dessa abordagem, argumenta-se que "os arquivistas devem ser centrados no usuário e abraçar oportunidades para usar a tecnologia para compartilhar conjuntos documentais, interagir com os usuários e melhorar a eficiência interna" (THEIMER, 2011b, p. 60, tradução nossa). Depreende-se, assim, a influência da tecnologia aplicada ao campo dos arquivos como característica de uma cultura do compartilhamento da informação no ambiente digital online.

Duas direções de debate convergem para os propósitos da presente investigação: a potencialidade do uso de recursos interativos da Web 2.0 e o aporte teórico da UX Design no cenário arquivístico. Assim, é oportuno expor brevemente alguns aspectos relacionados à evolução tecnológica da Web.

Concebido por Berners-Lee (1996), cerca de meio século após os trabalhos sobre o hipertexto, o projeto da World Wide Web mesclou técnicas de recuperação da informação com o hipertexto para dimensionar a criação de um sistema de informação em nível global. A Web tradicional (ou 1.0) consistiu em uma plataforma estática, uma espécie de vitrine informacional. Já na década de 2000, sua segunda geração popularizou-se como Web 2.0, agregando novos recursos como interoperabilidade, interatividade e arquitetura de participação: blogs, redes sociais, compartilhamento de vídeos on-line, computação na nuvem, etc. (O'REILLY, 2005).

Theimer (2011a, p. 126) pontua as mais significativas mudanças entre a primeira e a segunda gerações da Web: manifestação da rede como plataforma, possibilitando o acesso de dados desde qualquer local provido de conexão à internet; processo de abertura de inter- 
faces técnicas e padrões; websites voltados para a experiência de cada usuário; ampliação do sentido de interatividade, criação de conteúdo pelos usuários e integração da conexão entre estes. Compreendidas em conjunto, tais transformações modificaram a forma como indivíduos acessam e interagem com a informação disponibilizada na rede.

Outras gerações da Web já foram propostas vislumbrando alcançar novas tecnologias e linguagens, mas parte dos sítios eletrônicos das instituições arquivísticas hoje ainda busca se adaptar ao formato da Web 2.0, enquanto outra ainda está aprisionada à mentalidade da Web 1.0 (THEIMER, 2009). O cenário nacional não é diferente: como apontado por Mariz (2012, p.147), os arquivos brasileiros gerenciam tecnologias atuais com base em parâmetros criados por tecnologias anteriores.

A partir de levantamento realizado por Jardim (1999), observou-se que a porcentagem de websites de instituições arquivísticas públicas brasileiras que apresentavam, à época, instrumento de pesquisa on-line em base de dados era muito baixa, correspondendo a apenas $15 \%$ do total de sítios institucionais. Desde então, o autor destaca a necessidade de ampliação das informações contidas nos arquivos através dos instrumentos de pesquisa, incentivando mecanismos que proporcionem maior interatividade.

No ano subsequente, a elaboração de diretrizes pelo CONARQ recomendando a parametrização de informações dispostas nos websites das instituições arquivísticas brasileiras norteou, em um primeiro momento, a disposição e disseminação da informação sobre os arquivos na rede. Nessa direção, "a maioria dos arquivos percebeu o valor de usar a web para publicar informação sobre si e seus acervos - geralmente, na forma de colocar on-line instrumentos de pesquisa" (THEIMER, 2011a, p. 123, tradução nossa).

O advento da Web 2.0, o entrelaçamento virtual e célere do fluxo informacional, o surgimento da $\operatorname{ISAD}(G)$ e da NOBRADE, a ampliação das políticas de acesso à informação e a tendência de transparência e accountability ${ }^{2}$ na governança pública são fatores que acarretam o encurtamento da distância virtual entre o usuário e as instituições arquivísticas. Neste cenário, destaca-se um processo de transição dos instrumentos de pesquisa tradicionais, como o guia e o inventário impressos, por exemplo, para uma nova geração de instrumentos de pesquisa ou de referência on-line. Vale destacar que, para Andrade e Silva (2009), prioriza-se a terminologia instrumentos arquivísticos de referência ao invés de instrumentos de pesquisa, uma vez que tais ferramentas não comportariam em si mesmas as pesquisas, porém, artefatos referenciais.

De fato, as recentes tecnologias simplificaram a disseminação da informação descritiva (YEO, 2016); porém, será que essa informação se tornou mais simples para o seu usuário? Por esse prisma, o autor sinaliza uma lacuna quanto a iniciativas para identificar boas práticas em métodos de apresentação e recuperação da informação descrita, desconhecendo-se como a tecnologia afeta, com efeito, as possibilidades de uso das descrições: "na ausência de normas estabelecidas, os usuários, ao consultarem uma gama de recursos on-line, frequentemente precisam aprender uma nova interface e sintaxe de recuperação para cada site que visitam" (YEO, 2016, p. 152).

Gilliland-Swetland (2001) pontua que a inconsistência na forma de apresentação dos instrumentos de referência os torna incompreensíveis ao usuário leigo:

\footnotetext{
${ }^{2} \mathrm{O}$ termo accountability, comumente traduzido como prestação de contas ou responsabilização social, carrega um sentido ainda mais amplo. Além do ato de prestar contas, consistiria na obrigação em si da administração pública de prestar contas.
} 
Em geral, tanto os arquivistas como seus usuários utilizam a mesma versão do instrumento de pesquisa e versões simplificadas ou visualizações alternativas raramente são preparadas para o uso público. Embora a eficácia desta forma em facilitar o uso de materiais de arquivo nunca tenha sido sistematicamente examinada, todas as indicações são de que o instrumento de pesquisa como atualmente concebido desempenha um trabalho bastante fraco em direcionar as necessidades, práticas e comportamentos do usuário não acadêmico. (GILLILAND-SWETLAND, 2001, p. 200, tradução nossa).

A multiplicidade de demandas dos usuários dos arquivos enseja uma abordagem mais dinâmica e flexível, salientando uma renovação da maneira pela qual esses interagem com as instituições arquivísticas. Nesse bojo, a área de UX caminha ao encontro dessa necessidade, ao passo que é considerada uma recente área do Design e apresenta metodologias específicas para projetos de produtos digitais, com ênfase no design centrado no usuário ${ }^{3}$. De acordo com a definição dada pela norma internacional ISO 9241-210 (Human-centred design for interactive systems), o termo user experience corresponde às percepções e respostas dos usuários resultantes do uso e/ou antecipação do uso de um produto, sistema ou serviço.

Essa norma ainda complementa que a UX é consequência, dentre alguns fatores: da performance do sistema; do comportamento interativo; da capacidade assistiva do sistema interativo; além do estado físico e psicológico do usuário, a partir de suas experiências anteriores, preferências, percepções, habilidades e contexto de uso. Diante disso, fica evidente que a área se relaciona com várias disciplinas para se desenvolver.

Conforme o modelo elaborado por Saffer (2009), as relações interdisciplinares da área de $U X$ são apresentadas em um diagrama, circunscrevendo a navegação, por exemplo, às disciplinas de Arquitetura da Informação, Design Visual e Design de Interação. Yeo (2016) admite que há potencial para que a navegação se torne mais sofisticada em ambientes digitais por meio de "técnicas desconhecidas do mundo do papel". Contudo, reconhece que "os arquivistas ainda não sabem a melhor forma de tornar os instrumentos de pesquisa on-line navegáveis (browsable/navigable)" (YEO, 2016, p. 153).

Em especial, a Arquitetura de Informação (AI) trata de disciplina nuclear do UX Design, oferecendo aportes teóricos relevantes para o campo dos arquivos. Segundo Zwies (2000, p. 11, tradução nossa), é definida como "a arte e a ciência de organizar a informação para ajudar as pessoas a satisfazer suas necessidades de informação de forma efetiva [...] o que implica organizar, navegar, marcar e buscar mecanismos nos sistemas de informação". Logo, a Al relaciona-se mais com a estruturação física das informações, de modo a otimizar a navegação dos usuários pelos sistemas, do que propriamente com o conjunto de elementos que compõem as relações de interação dos usuários, pelo viés da $U X$.

Em estudo sobre a distinção dos conceitos de UX e usabilidade, Padovani, Schlemmer e Scariot (2012) promovem ampla revisão de literatura sobre a questão e inferem que, com a evolução do conceito tradicional de usabilidade, este fora encampado pelo termo user experience. Dessa forma, ressaltam que os "métodos de avaliação com envolvimento participativo dos usuários também podem ser utilizados para analisar a user experience" (PADOVANI; SCHLEMMER; SCARIOT, 2012, p. 8).

A partir do pressuposto de que o UX Design visa a tornar a relação usuário-sistema a mais espontânea e fluida possível, buscando evitar que o sistema se torne um obstáculo ao

\footnotetext{
3 Apesar da norma ISO 9241-210 sinalizar a preferência pelo termo human-centred design, na prática, considera-o como sinônimo ao termo user-centred design.
} 
usuário, percebe-se que esta área pode oferecer diversas contribuições à Arquivologia. Assim, destaca-se o potencial da $U X$ no tocante à elaboração de instrumentos arquivísticos de referência on-line que possam ser intuitivos, inteligíveis e agradáveis ao usuário. Para além de prover acesso, a difusão dos acervos arquivísticos por esses instrumentos deve evitar um produto ensimesmado, isto é: concebido de e para especialistas da área arquivística e/ou afins.

\section{ANÁLISE EMPÍRICA}

\subsection{Panorama do campo empírico}

Antigo Arquivo Público do Império, o AN figura como campo empírico desta investigação via SIAN, principal meio de acesso às informações relacionadas ao acervo que a instituição custodia.

A disponibilização on-line dessa base de dados remete ao início dos anos 2000, apresentando-se como portal de acesso às informações relacionadas ao acervo arquivístico do AN. Atualmente, o SIAN tem versões nos idiomas inglês e espanhol, além do português, e é composto por 937 fundos e 1.073.491 dossiês publicados ${ }^{4}$. O acesso ao sistema é obtido mediante o cadastro do usuário em seu sítio eletrônico, fornecendo informações pessoais relacionadas à sua identificação, documentação e endereço eletrônico.

O levantamento de dados sobre o acesso ao sistema compreendeu o intervalo entre os meses de fevereiro de 2016 a fevereiro de 2017, totalizando 343.021 acessos $^{5}$ ao SIAN. Neste período, destaca-se uma importante mudança de interface. A nova interface entrou "no ar" no dia 29 de agosto de 2016, sofrendo manutenções para a estabilização do sistema por cerca de 45 dias.

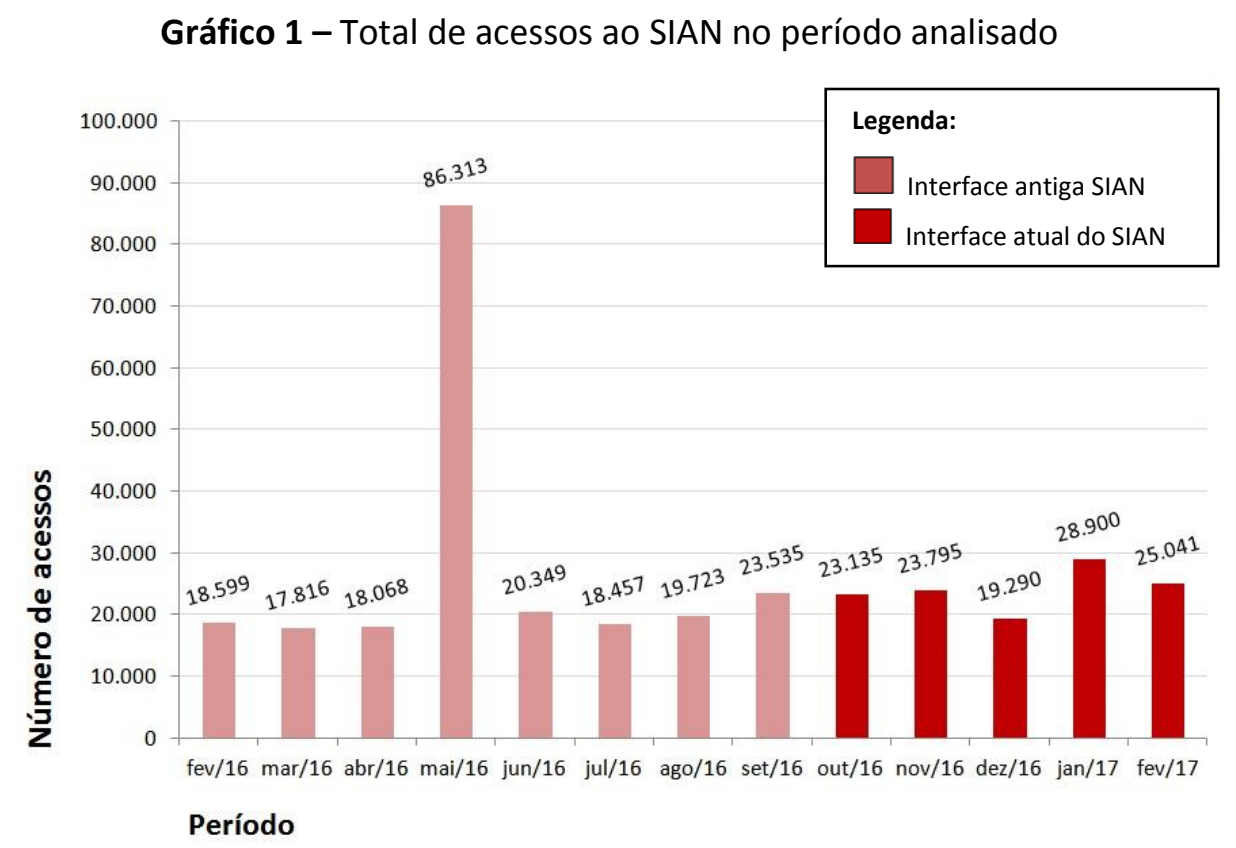

Fonte: Elaborado pela autora (2017), a partir de informações fornecidas pela Coordenação de Tecnologia da Informação (COTIN/AN).

\footnotetext{
${ }^{4}$ Disponível em: http://sian.an.gov.br/sianex/log/estatistica.asp. Acesso em: 08 jun. 2017.

${ }^{5}$ A compilação dos dados quantitativos de acessos foi realizada pelo administrador de rede da instituição, observando-se que este número refere-se a "visitas únicas", que identifica o usuário e consolida as páginas acessadas.
} 
Como apontado no Gráfico 1, apenas a partir de outubro de 2016 a nova interface do SIAN foi disponibilizada já com os ajustes técnicos necessários. Como principais alterações dessa interface, observa-se uma barra superior vermelha abaixo do título do sistema, contendo nove abas: Página Inicial (representada por um ícone); Fundos/Coleções; MAPA; Favoritos; Estatística; Editar Cadastro; Contatos; Ajuda e Sair.

Fato interessante é que os acessos realizados ao SIAN ultrapassam os limites do país. Conforme dados fornecidos pela Coordenação de Tecnologia da Informação (COTIN/AN), outros países também utilizam essa ferramenta para buscar acervos arquivísticos brasileiros: após a América do Sul, com 91,34\% do total de consultas, o maior percentual de consultas provém da Europa $(5,28 \%)$ e América do Norte $(2,2 \%)$, em seguida. A quantidade de acessos nos demais continentes é inexpressiva, segundo dados fornecidos pela COTIN/AN.

Quanto à distribuição do quantitativo de acessos por país, os três países que mais utilizaram o SIAN no período analisado foram, após o Brasil, respectivamente, Itália, Estados Unidos e Portugal.

Em relação aos fundos e coleções mais consultados pelos usuários em 2016, após filtragem por critério quantitativo superior a 2.500 ocorrências de acesso, 17 fundos se destacaram, tendo sido o fundo "Divisão de Polícia Marítima, Aérea e de Fronteiras" o mais acessado com um total de 1.130.265 acessos, logo após, seguido pelo fundo "Serviço de Polícia Marítima, Aérea e de Fronteiras - SP (Santos)", com 141.236 acessos, de acordo com informações da COTIN/AN.

\subsection{Trilhando o percurso metodológico}

Foi proposta a combinação de duas metodologias com duas normas técnicas relacionadas à temática de usabilidade (Quadro 1). Tal adaptação encontra respaldo na ideia de que tanto normas como métodos de usabilidade denotam uma relação de complementaridade para a análise do sistema objeto desta investigação.

Quadro 1 - Quesitos de análise segundo o método selecionado

\begin{tabular}{|l|l|}
\hline \multicolumn{1}{|c|}{ Método selecionado } & \multicolumn{1}{c|}{ Quesitos analisados } \\
\hline SUS (BROOKE, 1986) & 10 perguntas relacionadas à efetividade, eficiência e satisfação. \\
\hline \multirow{4}{*}{ NBR ISO/IEC 9126-1 (2003) 6} & $\begin{array}{l}\text { Inteligibilidade: facilidade do usuário em reconhecer a lógica de funcionamen- } \\
\text { to do produto e sua aplicação. }\end{array}$ \\
\cline { 2 - 2 } & Atratividade: evidencia a satisfação subjetiva do usuário durante o uso. \\
\cline { 2 - 2 } & Apreensibilidade: medida da facilidade de utilização do software pelo usuário. \\
\cline { 2 - 2 } & Operacionalidade: medida da facilidade de operação do sistema. \\
\hline \multirow{4}{*}{ NBR ISO 9241-11 (1998) } & Eficácia: recursos gastos em relação à acurácia e abrangência. \\
\cline { 2 - 2 } $\begin{array}{l}\text { Avaliação heurística da } \\
\text { usabilidade (NIELSEN, }\end{array}$ & $\begin{array}{l}\text { Satisfação: ausência do desconforto e presença de atitudes positivas para com } \\
\text { o uso de um produto. }\end{array}$ \\
\hline 1995) & $\begin{array}{l}\text { Ajuda e documentação: o sistema deve fornecer mecanismos de ajuda e do- } \\
\text { cumentação concretos e breves, apresentando a informação de modo que seja } \\
\text { facilmente encontrada e focada nas tarefas do usuário. }\end{array}$ \\
\cline { 2 - 2 } & $\begin{array}{l}\text { Controle do usuário: utilização da linguagem do usuário, com conceitos que } \\
\text { Ihes são familiares ao invés de termos especializados do sistema. }\end{array}$ \\
\hline
\end{tabular}

Fonte: Elaborado pela autora (2017).

Criado em 1986 por Brooke (2013), o SUS trata de uma metodologia de grande repercussão pelo mundo, apresentando um questionário com dez questões capazes de abran-

\footnotetext{
${ }^{6}$ A norma brasileira NBR ISO/IEC 9126-1 corresponde à norma internacional ISO/IEC 9126, criada em 1991.
} 
ger uma visão global do usuário sobre o sistema, em que o respondente assinala a sua resposta de acordo com uma escala Likert.

A partir da adaptação proposta, as respostas obtidas que escapavam aos critérios de avaliação do SUS foram analisadas, complementarmente, sob o viés de duas normas técnicas relacionadas à usabilidade, a saber, NBR ISO/IEC 9126-1 e NBR ISO 9241-11 (ABNT, 2003a, 2003b), e da avaliação heurística de usabilidade elaborada pelo cientista da computação Jakob Nielsen (1995).

Segundo Boucinha e Tarouco (2013, p. 3), a NBR ISO/IEC 9126-1 trata da primeira norma internacional que aborda o conceito de usabilidade, definindo para esta cinco subcaracterísticas: inteligibilidade, apreensibilidade, operacionalidade, atratividade e conformidade. Já a norma NBR ISO 9241-11 apresenta a definição de novos termos para a compreensão do conceito de usabilidade, como eficácia, eficiência, satisfação, contexto de uso e sistema de trabalho.

Por sua vez, a metodologia de avaliação heurística de usabilidade de Nielsen (1995) consiste em uma técnica preditiva para a avaliação sistemática da interface do usuário no tocante à sua usabilidade, tratando-se de um método tradicional. Originalmente, o método proposto pelo autor para a avaliação de interfaces envolve dez heurísticas. Contudo, a análise aqui empreendida abarcou apenas duas destas aplicáveis ao escopo da pesquisa: controle do usuário e ajuda e documentação.

\subsection{Análise da experiência do usuário sobre o SIAN}

Durante o período de 30 de maio de 2017 a 30 de junho de 2017, foram obtidas 46 respostas completas ao questionário, uma vez que todas as questões eram obrigatórias para a sua conclusão. A pesquisa foi divulgada em quatro grupos da rede social Facebook que englobam, predominantemente, a temática Arquivologia no contexto brasileiro. Além de tais grupos, a pesquisa também foi divulgada na página oficial da mesma rede social do AN, no intuito de alcançar os usuários de seu próprio instrumento de referência; em uma lista de discussão, por e-mail, de profissionais brasileiros ligados ao ensino da Arquivologia; e em grupos do Facebook de cursos universitários de História, admitindo-se que há um potencial público desta área que utiliza a ferramenta SIAN.

No tocante à sua primeira parte, as respostas sobre o perfil dos respondentes demonstram um predomínio de usuários relacionados ao campo teórico ou empírico dos arquivos, totalizando 34 pessoas. Oito são pesquisadores de outras áreas e apenas quatro não se enquadram nas opções anteriores, o que os aproxima da concepção de "cidadão comum". Nesse sentido, nota-se que há uma baixa proporção de respondentes $-8,7 \%$ - relacionada a usuários não especializados em pesquisas, de modo geral, ou na matéria arquivística. Presume-se que isso se deve, parcialmente, à dificuldade de aplicação do questionário a um público diversificado, o que demandaria a elaboração de novas estratégias para abarcar essa categoria de usuários.

O quantitativo de respondentes se mostrou menor na faixa etária entre 39 e 48 anos seis pessoas - e maior entre 29 a 38 anos -18 pessoas. 0 restante das faixas denotou um equilíbrio: 11 respondentes entre 18 e 28 anos e o mesmo número entre igual ou acima de 49 anos. Por sua vez, o nível educacional dos respondentes refletiu diferentes gradações: 22

\footnotetext{
${ }^{7}$ Baseado em 294 tipos de erros de usabilidade, o dinamarquês Jakob Nielsen propôs como parâmetro para a avaliação da usabilidade de websites dez itens de análise, as heurísticas.
} 
têm ensino superior completo; sete, doutorado incompleto; seis, superior incompleto; seis, doutorado completo; dois, mestrado completo e mais três, mestrado incompleto.

Quadro 2 - Fundos/relação entre as perguntas fechadas do questionário e a metodologia utilizada

\begin{tabular}{|c|c|c|}
\hline Pergunta do questionário & Metodologia de análise & Núcleo conceitual do quesito analisado \\
\hline $\begin{array}{l}\text { A página inicial do SIAN explica com } \\
\text { clareza como pode ele ser utilizado? }\end{array}$ & NBR ISO/IEC 9126-1 & $\begin{array}{l}\text { Inteligibilidade: facilidade do usuário em } \\
\text { reconhecer a lógica de funcionamento do } \\
\text { produto e sua aplicação. }\end{array}$ \\
\hline O visual do sistema era atrativo? & NBR ISO/IEC 9126-1 & $\begin{array}{l}\text { Atratividade: evidencia a satisfação subje- } \\
\text { tiva do usuário durante o uso. }\end{array}$ \\
\hline \multirow{2}{*}{$\begin{array}{l}\text { O sistema lhe ofereceu algum recur- } \\
\text { so de ajuda durante a pesquisa? }\end{array}$} & $\begin{array}{l}\text { Avaliação heurística da } \\
\text { usabilidade (Nielsen) }\end{array}$ & Ajuda e documentação. \\
\hline & NBR ISO/IEC 9126-1 & $\begin{array}{l}\text { Operacionalidade: medida da facilidade de } \\
\text { operação do sistema. }\end{array}$ \\
\hline \multirow{2}{*}{$\begin{array}{l}\text { Você precisou aprender novos co- } \\
\text { nhecimentos ou habilidades técnicas } \\
\text { para conseguir utilizar esse sistema? }\end{array}$} & SUS & $\begin{array}{l}\text { Eu precisei aprender várias coisas novas } \\
\text { antes de conseguir usar o sistema. }\end{array}$ \\
\hline & NBR ISO/IEC 9126-1 & $\begin{array}{l}\text { Apreensibilidade: medida da facilidade de } \\
\text { utilização do software pelo usuário. }\end{array}$ \\
\hline $\begin{array}{l}\text { Você precisou ou precisaria da ajuda } \\
\text { de uma pessoa com conhecimentos } \\
\text { técnicos para utilizar o sistema? }\end{array}$ & SUS & $\begin{array}{l}\text { Eu acho que precisaria de ajuda de uma } \\
\text { pessoa com conhecimentos técnicos para } \\
\text { usar o sistema. }\end{array}$ \\
\hline $\begin{array}{l}\text { Qual o grau de complexidade da } \\
\text { linguagem utilizada pelo sistema? }\end{array}$ & SUS & $\begin{array}{l}\text { Eu acho o sistema desnecessariamente } \\
\text { complexo. }\end{array}$ \\
\hline $\begin{array}{l}\text { Qual o grau de dificuldade para } \\
\text { conseguir realizar a sua pesquisa? }\end{array}$ & SUS & Eu achei o sistema fácil de usar. \\
\hline $\begin{array}{l}\text { Você conseguiu encontrar a infor- } \\
\text { mação que procurava? }\end{array}$ & NBR ISO 9241-11 & $\begin{array}{l}\text { Eficácia: recursos gastos em relação à } \\
\text { acurácia e abrangência com as quais usuá- } \\
\text { rios atingem objetivos. }\end{array}$ \\
\hline $\begin{array}{l}\text { De uma maneira geral, qual o seu } \\
\text { grau de satisfação com a utilização } \\
\text { do sistema? }\end{array}$ & NBR ISO 9241-11 & $\begin{array}{l}\text { Satisfação: ausência do desconforto e } \\
\text { presença de atitudes positivas para com o } \\
\text { uso de um produto. }\end{array}$ \\
\hline $\begin{array}{l}\text { Você voltaria a usar o SIAN para } \\
\text { outras pesquisas? }\end{array}$ & SUS & $\begin{array}{l}\text { Eu acho que gostaria de usar esse sistema } \\
\text { com frequência. }\end{array}$ \\
\hline $\begin{array}{l}\text { Marque todas as suas impressões ao } \\
\text { utilizar o SIAN: }\end{array}$ & ---- & ---- \\
\hline \multirow[t]{2}{*}{ Satisfação } & NBR ISO 9241-11 & $\begin{array}{l}\text { Satisfação: ausência do desconforto e } \\
\text { presença de atitudes positivas para com o } \\
\text { uso de um produto. }\end{array}$ \\
\hline & NBR ISO/IEC 9126-1 & $\begin{array}{l}\text { Atratividade: evidencia a satisfação subje- } \\
\text { tiva do usuário durante o uso. }\end{array}$ \\
\hline Familiaridade & $\begin{array}{l}\text { Avaliação heurística da } \\
\text { usabilidade (Nielsen) }\end{array}$ & Controle do usuário. \\
\hline Facilidade & SUS & Eu achei o sistema fácil de usar. \\
\hline Esclarecimento & SUS & $\begin{array}{l}\text { Eu imagino que as pessoas aprenderão } \\
\text { como usar esse sistema rapidamente. }\end{array}$ \\
\hline Frustração & SUS & $\begin{array}{l}\text { Eu acho que o sistema apresenta muita } \\
\text { inconsistência. }\end{array}$ \\
\hline Estranhamento & SUS & $\begin{array}{l}\text { Eu acho o sistema desnecessariamente } \\
\text { complexo. }\end{array}$ \\
\hline Dificuldade & SUS & Eu achei o sistema atrapalhado de usar. \\
\hline Confusão & SUS & Eu achei o sistema atrapalhado de usar. \\
\hline
\end{tabular}

Fonte: Elaborado pela autora (2017). 
Quanto aos principais interesses de pesquisa no SIAN, observa-se a predominância da pesquisa acadêmica, apontada por 32 respondentes $(69,6 \%)$, seguida por interesse profissional $(56,5 \%)$ e pessoal (32,5\%). A necessidade por alguma informação específica empata com a opção curiosidade, sendo cada uma apontada por $19,6 \%$ dos respondentes.

Para fins de análise (vide Quadro 2), algumas relações são estabelecidas entre as perguntas fechadas do questionário, a metodologia de análise utilizada para cada uma e o respectivo núcleo conceitual que envolve o quesito analisado.

A análise das respostas às questões abertas realça algumas questões apontadas a seguir. Para $43,4 \%$ dos respondentes, há pouca clareza quanto às informações dispostas na página inicial do SIAN e apenas $10,9 \%$ acham que a página se utiliza de muita clareza. 0 visual do sistema é pouco atrativo para $54,4 \%$ dos usuários - apenas um deles avaliou o sistema como muito atrativo. Segundo $65,2 \%$ dos respondentes, o sistema não ofereceu recurso de ajuda durante a pesquisa. Entretanto, 63\% dos usuários alegou que não precisou aprender conhecimentos e habilidades técnicas novos para o uso do SIAN. Sobre a necessidade de auxílio de alguém com conhecimentos técnicos para utilizar o sistema, 54,3\% das pessoas responderam positivamente.

Quanto ao grau de complexidade da linguagem utilizada pelo sistema, 87\% dos respondentes a julgaram como complexa a muito complexa, o que se refletiu na dificuldade para realização da pesquisa: $82,6 \%$ das respostas indicavam esse problema. Apesar da dificuldade, 54,3\% dos usuários afirmaram ter encontrado a informação que desejavam. O grau de satisfação apontado sobre a utilização do sistema pendeu para a insatisfação, visto que $41,3 \%$ dos respondentes se mostrou pouco satisfeito, enquanto a mesma porcentagem não externou satisfação ou insatisfação. Curiosamente, $84,8 \%$ dos usuários responderam que voltariam a utilizar o SIAN para outras pesquisas.

Sobre as impressões ao utilizar o sistema, as três mais indicadas pelos usuários foram, respectivamente: dificuldade $(54,3 \%)$, confusão $(54,3 \%)$ e estranhamento $(45,7 \%)$. Digno de nota é que, menos apontadas, figuram familiaridade (10,9\%) e facilidade (13\%).

Por fim, a última pergunta do questionário proporcionou uma abordagem qualitativa de análise, visto que se tratava de uma questão aberta. Diante do questionamento sobre possíveis melhorias no sistema, um extrato de 10 respostas foram selecionadas para análise (Quadro 3), desprezando-se respostas que optaram não declarar contribuição alguma ou as que, de algum modo, não apresentavam conteúdo relevante para o escopo desta pesquisa.

Quadro 3 - Respostas selecionadas para análise qualitativa sobre a pergunta aberta do questionário

(continua)

\section{Comentários redigidos pelos respondentes} Primeiramente, o acesso ao sistema a partir da página do arquivo nacional: tive muitas dificuldades para acessar o SIAN a partir daquela página. E ainda, a questão da disponibilização da informação. Eu não sou arquivista e entendo pouco de descrição arquivística, procurei informações para uma disciplina que leciono na Biblioteconomia, mas encontrei muita dificuldade para acessar o conteúdo requerido pelo fato de a linguagem estar muito específica.

Fonte: Elaborado pela autora (2017).

* Os comentários apresentados foram transcritos exatamente como redigidos pelos respondentes.

\section{Análise qualitativa realizada}

A questão do controle do acesso via cadastro é uma crítica recorrente. Outro ponto colocado é a linguato de operacionalidade quanto inteligibilidade da norma NBR ISO/IEC 9126-1. Trata-se de um exemplo rio. gem específica, que se relaciona tanto com o conceique ilustra que o sistema não está centrado no usuá- 
Quadro 3 - Respostas selecionadas para análise qualitativa sobre a pergunta aberta do questionário

\begin{tabular}{|c|c|}
\hline & (continuação) \\
\hline Comentários redigidos pelos respondentes & Análise qualitativa realizada \\
\hline $\begin{array}{l}\text { Tornar mais simples e mais intuitivo. Termos e Jar- } \\
\text { gões da área arquivística poderiam ser transformados } \\
\text { em palavras de entendimento comum. }\end{array}$ & $\begin{array}{l}\text { Além da linguagem específica, esse comentário des- } \\
\text { taca o fato do sistema ser desnecessariamente com- } \\
\text { plexo, uma das perguntas do SUS. }\end{array}$ \\
\hline $\begin{array}{l}\text { Uma linguagem mais acessível às pessoas não familia- } \\
\text { rizadas com a dinâmica de busca. }\end{array}$ & $\begin{array}{l}\text { A falta de familiaridade com a dinâmica de busca } \\
\text { pode sugerir a necessidade de uma pessoa com co- } \\
\text { nhecimentos técnicos para utilizar o sistema (SUS). }\end{array}$ \\
\hline Uma maior divulgação e um bom passo a passo. & $\begin{array}{l}\text { Destaca-se a heurística de usabilidade de Nielsen } \\
\text { "Ajuda e documentação". }\end{array}$ \\
\hline $\begin{array}{l}\text { O sistema deveria ser de mais fácil acesso a pesquisa- } \\
\text { dores, estudantes, mas principalmente ao usuário } \\
\text { comum. }\end{array}$ & $\begin{array}{l}\text { A facilidade de acesso remete à apreensibilidade da } \\
\text { norma NBR ISO/IEC 9126-1, assim como à inteligibili- } \\
\text { dade. }\end{array}$ \\
\hline $\begin{array}{l}\text { Uma interface mais amigável, com explicações claras } \\
\text { para o público leigo e maior facilidade de entender as } \\
\text { subdivisões, além de uma busca mais fácil. A lingua- } \\
\text { gem facilitada seria um grande diferencial para quem } \\
\text { não tem formação em Arquivologia, por exemplo. }\end{array}$ & $\begin{array}{l}\text { Uma interface mais amigável requer o conceito de } \\
\text { atratividade, presente na norma NBR ISO/IEC 9126-1. } \\
\text { A facilidade da linguagem remete novamente à apre- } \\
\text { ensibilidade da mesma norma, enquanto uma busca } \\
\text { mais fácil alude à complexidade de uma das pergun- } \\
\text { tas do SUS. }\end{array}$ \\
\hline Uma linguagem mais palatável para o grande público. & $\begin{array}{l}\text { Operacionalidade e inteligibilidade da norma NBR } \\
\text { ISO/IEC 9126-1. }\end{array}$ \\
\hline $\begin{array}{l}\text { As informações estarem expostas de forma mais clara } \\
\text { e intuitiva para o usuário. }\end{array}$ & $\begin{array}{l}\text { Destaca-se a necessidade de inteligibilidade do siste- } \\
\text { ma (norma NBR ISO/IEC 9126-1). }\end{array}$ \\
\hline $\begin{array}{l}\text { Melhor interface com o usuário, facilitar as formas de } \\
\text { recuperação da informação, disposição dos dados } \\
\text { mais simples, claras, diretas. Exclusão de metadados } \\
\text { sem descrição. }\end{array}$ & $\begin{array}{l}\text { O comentário mostra a ausência de controle do usuá- } \\
\text { rio (heurística de Nielsen) e a insuficiência do concei- } \\
\text { to de atratividade, presente na norma NBR ISO/IEC } \\
9126-1 .\end{array}$ \\
\hline $\begin{array}{l}\text { A linguagem utilizada deveria ser mais voltada para o } \\
\text { usuário, de modo geral. Sou da área de arquivos e } \\
\text { tenho dificuldades em fazer uma busca simples, } \\
\text { mesmo conhecendo a estrutura multinível da descri- } \\
\text { ção e os termos técnicos. Imagino que alguém sem } \\
\text { esse conhecimento tenha ainda mais dificuldades. }\end{array}$ & $\begin{array}{l}\text { Interessante notar que alguém da própria área tem } \\
\text { dificuldades. Isso aponta para o fato do sistema ser } \\
\text { desnecessariamente complexo e a necessidade de } \\
\text { novos aprendizados antes de conseguir usar o siste- } \\
\text { ma, duas perguntas do SUS. Além disso, o comentário } \\
\text { remete ao conceito de operacionalidade (norma NBR } \\
\text { ISO/IEC 9126-1). }\end{array}$ \\
\hline
\end{tabular}

Fonte: Elaborado pela autora (2017).

* Os comentários apresentados foram transcritos exatamente como redigidos pelos respondentes.

\section{CONSIDERAÇÕES FINAIS}

Os dados empíricos coletados na pesquisa apontam para a compreensão da percepção dos usuários sobre o SIAN a partir de sua experiência de uso, identificando aspectos do sistema passíveis de melhorias e estimulando ações corretivas, no intuito de facilitar e otimizar o acesso e a inteligibilidade desse instrumento, de modo a lograr maior grau de satisfação por seus usuários.

Como problemas de usabilidade mais críticos, surgem: a clareza do sistema para os usuários; a necessidade de recursos de ajuda para melhor orientá-los quanto aos mecanismos de busca na base de dados; o uso excessivo de termos técnicos e a complexidade da linguagem utilizada, de maneira geral. Todos esses pontos ratificam as principais impressões dos usuários respondentes sobre os sistemas, reforçando a dificuldade, o estranhamento e a frustração quanto ao uso do SIAN. 
As respostas à pergunta aberta também foram importantes para ratificar a reincidência de comentários predominantemente concentrados sobre a clareza da interface, da linguagem utilizada e da acessibilidade. Várias respostas mencionam a necessidade de um acesso mais simples para o "usuário comum", "usuário em geral" ou, ainda, "grande público". É sintomático notar que, embora grande parte dos respondentes seja familiarizada com a área de arquivos ou pesquisas em outras áreas (91,3\%), muito se critica sobre a linguagem utilizada.

Nesse sentido, em que pesem os recursos tecnológicos já utilizados pelo AN para a ampliação dos usos e usuários de seus acervos, importa incentivar mais pesquisas sobre a relação sistema-usuário. Por ora, há indícios de que o SIAN deva ser revisto, considerando a melhoria dos pontos mais fragilizados; em especial, a inteligibilidade, a operacionalidade e a apreensibilidade do sistema, abarcando pluralidade do público que acessa os arquivos, bem como aquele que não o visita comumente.

À medida que os usuários dos arquivos interagem com os acervos descritos na etapa de difusão, a adoção de uma abordagem centrada nestes é primordial para o debate da descrição arquivística e suas normas. Por essa direção, repensar o papel dos instrumentos arquivísticos de referência constitui-se em exercício crítico que demanda, para além do foco sobre os usuários, a percepção dos contextos tecnológico, cognitivo e sociopolítico.

Ao invés de delimitar fronteiras disciplinares para melhor compreender os arquivos, "deslimitá-las" pode ser uma saída - e também um desafio. No âmbito da difusão arquivística, a interlocução proposta entre a Arquivologia e as áreas relacionadas às tecnologias digitais, a exemplo do Design de Interação, possibilitou agregar novos elementos ao debate, elevando o patamar da discussão à conjuntura atual.

Por fim, a dimensão social dos arquivos se relaciona intimamente à capacidade destes se comunicarem com a sociedade, o que ultrapassa o mero provimento de acesso à informação que detêm aos cidadãos. O potencial comunicacional dos arquivos reside na capacidade destes difundirem seus acervos sob a forma de produtos e serviços, de modo a tornar a informação esclarecida para o público que deles faz uso. Nessa direção, o UX Design desponta como um caminho possível para qualificar o acesso aos arquivos, apostando em critérios de usabilidade para aprimorar recursos e funcionalidades dessa nova geração de instrumentos de referência on-line.

\section{REFERÊNCIAS}

ALBERCH I FUGUERAS, R. Ampliación del uso social de los archivos. Estrategias y perspectivas. Seminário Internacional de Arquivos de Tradição Ibérica. Rio de Janeiro, 2000.

ANDRADE, R. S.; SILVA, R. R. G. Aspectos teóricos e históricos da descrição arquivística e uma nova geração de instrumentos arquivísticos de referência. PontodeAcesso, Salvador, v. 2, n. 3, p. 14-29, 2008.

ANDRADE, R. S.; SILVA, R. R. G. Uma nova geração de instrumentos arquivísticos de referência: a publicação dos produtos das descrições arquivísticas em meio eletrônico. Simpósio Baiano de Arquivologia, v. 2, 2009.

ARQUIVO NACIONAL. Dicionário Brasileiro de Terminologia Arquivística. Rio de Janeiro: Arquivo Nacional, 2005. 232 p. 
ASSOCIAÇÃO BRASILEIRA DE NORMAS TÉCNICAS. NBR ISO 9241-11: Requisitos Ergonômicos para Trabalho de Escritórios com Computadores: Parte 11 - Orientações sobre Usabilidade. Rio de Janeiro, p. 21. 2003a.

ASSOCIAÇÃO BRASILEIRA DE NORMAS TÉCNICAS. NBR ISO/IEC 9126-1: Engenharia de software - Qualidade de produto: Parte 1 - Modelo de qualidade. Rio de Janeiro, p. 21. 2003b.

BELLOTTO, H. L. Arquivos permanentes: tratamento documental. Rio de Janeiro: FGV, 2006.

BERNERS-LEE, T. WWW: Past, present, and future. Computer, v. 29, n. 10, p. 69-77, 1996. Disponível em: https://www.w3.org/People/Berners-Lee/1996/ppf.html. Acesso em: 07 jun. 2017.

BERNERS-LEE, T., LASSILA, O.; HENDLER, James. The semantic web. Scientific American, Maio, 2001.

BOUCINHA, R. M.; TAROUCO, L. M. R. Avaliação de Ambiente Virtual de Aprendizagem com o uso do SUS-System Usability Scale. RENOTE, v. 11, n. 3, 2013.

BROOKE, J. SUS: a retrospective. Journal of usability studies, v. 8, n. 2, p. 29-40, 2013.

CHAVES, M. A. Difusão nos arquivos: difundir o quê. Actas del XII Congreso de Archivología del MERCOSUR / Angelly Arancibia Noriel. Compilado por Sofía Brunero.Córdoba: Redes, 2017.

CONSELHO NACIONAL DE ARQUIVOS. Diretrizes Gerais para a Construção de Websites de Instituições Arquivísticas. Rio de Janeiro: Conarq, 2000. Disponível em:

http://www.portalan.arquivonacional.gov.br/Media/conarqwebsites.pdf. Acesso em: 15 nov. 2016.

CRUCES BLANCO, E. La divulgación em lós archivos. El gran público y el derecho de conocer los archivos. In: CRUCES, E.; AQUESOLO, J. (Coord.): iLo que hay que ver! La divulgación en el Archivo Histórico Provincial de Málaga: El Documento del mes. Cádiz: Junta de Andalucía. Consejería de Cultura, 2007, p. 13-24.

DUCHEIN, M. Los obstáculos que se oponen al acceso, a la utilización y a la transferencia de la información conservada en los archivos: un estudio del RAMP. Paris: Unesco, 1983.

DURANTI, L. Structural and formal analysis: the contribution of diplomatics to archival appraisal in the digital environment. In: HILL, J. (Ed.). The future of archives and recordkeeping: a reader. London: Facet Publishing, 2011.

FOUCAULT, M. A arqueologia do saber. Rio de Janeiro: Forense Universitária, 2010.

GILLILAND-SWETLAND, A. J. Popularizing the finding aid: exploiting EAD to enhance online discovery and retrieval in archival information systems by diverse user groups. Journal of internet cataloging, v. 4, n. 3-4, p. 199-225, 2001. 
HERRERA, A. H. Archivística general: teoría y práctica. 1991.

InterPARES Trust. Comments on Records in Context. 2016. Disponível em: https://interparestrustblog.files.wordpress.com/2016/12/interparestrust commentsonric fi nal2.pdf. Acesso em: 07 jun. 2017.

JARDIM, J. M. O acesso à informação arquivística no Brasil: problemas de acessibilidade e disseminação. Mesa redonda Nacional de Arquivos. Rio de Janeiro, 1999.

LLANES PADRÓN, D. La descripción archivística en los tiempos posmodernos: conceptos, principios y normas. Marília: Cultura Acadêmica, 2016.

MACNEIL, H. Picking our text: archival description, authenticity, and the archivist as editor. The American Archivist, v. 68, n. 2, 2005.

MARIZ, A. C. A. A informação na internet: arquivos públicos brasileiros. Rio de Janeiro: FGV, 2012.

NIELSEN, J. How to Conduct a Heuristic Evaluation. 1995. Disponível em: http://www. nngroup.com/articles/how-to-conduct-a-heuristic-evaluation/. Acesso em: 11 nov. 2016.

NORA, P. Entre memória e história: a problemática dos lugares. Projeto História, São Paulo, n. 10, dez. 1993, p.7-28.

OLIVEIRA, L. M. V. Modelagem e status científico na descrição arquivística no campo dos arquivos pessoais. 2010. Tese (Doutorado em Ciências - História Social). Universidade de São Paulo, São Paulo, 2010.

O'REILLY, T. What is Web 2.0: Design patterns and business models for the next generation of software. O'Reilly Publishing, 2005.

PADOVANI, S.; SCHLEMMER, A.; SCARIOT, C. A. Usabilidade \& user experience, usabilidade versus user experience, usabilidade em user experience?: uma discussão teóricometodológica sobre comunalidades e diferenças. In: CONGRESSO INTERNACIONAL DE ERGONOMIA E USABILIDADE DE INTERFACES HUMANO -COMPUTADOR, 12., 2012. Anais [...]. Natal, 2012.

ROCKEMBACH, M. Difusão em arquivos: uma função arquivística, informacional e comunicacional. Informação arquivística, v. 4, n. 1, 2015.

ROUSSEAU, J.-Y.; COUTURE, C. Os fundamentos da disciplina arquivística. Lisboa: Dom Quixote, 1998.

SAFFER, D. The Disciplines of User Experience. Kicker Studio, 2009. Disponível em: www.kickerstudio.com/2008/12/the-disciplines-of-user-experience. Acesso em: 04 jun. 2017. 
THEIMER, K. Interactivity, flexibility and transparency: social media and Archives 2.0. In: HILL, J. (Ed.). The future of archives and recordkeeping: a reader. London: Facet Publishing, 2011a.

THEIMER, K. Web 2.0 tools and strategies for archives and local history collections. NealSchuman Publishers, Inc., 2009.

THEIMER, K. What is the Meaning of Archives 2.0?. The American Archivist, v. 74, n. 1, p. 58$68,2011 b$.

YAKEL, E. Archival Representation. Archival Science, v. 3, n. 1, p. 1-25, 2003.

YEO, G. Debates em torno da descrição. In: EASTWOOD, T.; MACNEIL, H. (Orgs.). Correntes atuais do pensamento arquivístico. Belo Horizonte: UFMG, 2016.

ZWIES, R. Observations on the American society for information science summit 2000 meeting: defining information architecture. Bulletin of the American Society for Information Science and Technology, v. 26, n. 5, p. 10-12, 2000. 